\title{
And Ghana was scared: Media Representations of the Risk of an Ebola Outbreak in Ghana
}

\section{Iddrisu Seidu}

Head of Research and Programs, Center for Development and Policy Advocacy, Box TL 1233, Tamale, Ghana

\begin{abstract}
Introduction: The 2014 Ebola virus outbreak in parts of West Africa marked the $25^{\text {th }}$ occurrence of the disease since its discovery in 1976. While earlier outbreaks in Central and Eastern Africa had limited geographical extension and little media coverage, news media interest in the 2014 epidemic was remarkably high. In countries like Ghana, where the risk of imported infection was estimated to be among the highest, news coverage for the epidemic proliferated. This study aimed to describe and analyze the central themes which characterized media representations of the risk of Ebola outbreak in Ghana.

Method: A quantitative content analysis (CA) was employed to study news media reportage of the risk of Ebola outbreak in Ghana. Two daily newspapers, the Daily Graphic and Today were sampled. An online search for Ebola news stories in the selected newspapers was conducted, and all hits with Ebola downloaded and screened. A total of 332 articles were retrieved and 156 articles met the inclusion criteria. Three independent coders carried out the coding using identical story analysis form.

Results: In the course of the 2014 Ebola epidemic in parts of West Africa, the Daily Graphic and Today newspapers in Ghana published 332 stories about the epidemic. Of this number, the study analyzed 156 news articles which met the inclusion criteria. The analysis found that, media coverage for the risk of Ebola outbreak in Ghana reflected nine salient themes: concerns about the Ghana's preparedness, support for Ghana's preparation, public education on Ebola virus, assurances on Ghana's readiness, suspected cases of Ebola, effects of Ebola, critique of Ebola risk handling, Misinformation and other.

Conclusion: Analysis of news media coverage for the threat of Ebola outbreak in Ghana revealed nine important themes. These themes, contributed to an understanding of the broad impact of the recent Ebola outbreak on various sectors of the population.

Key words: media coverage, Ebola threat in Ghana, epidemic preparedness, 2014 West Africa Ebola outbreak Correspondence: saha.seidu1@gmail.com

DOI: $10.5210 /$ ojphi.v10i2.9229

Copyright @2018 the author(s)

This is an Open Access article. Authors own copyright of their articles appearing in the Online Journal of Public Health Informatics. Readers may copy articles without permission of the copyright owner(s), as long as the author and OJPHI are acknowledged in the copy and the copy is used for educational, not-for-profit purposes.
\end{abstract}

\section{Introduction}

The 2014 Ebola virus disease (EVD) outbreak in parts of West Africa marked the 25 ${ }^{\text {th }}$ occurrence of the disease since its discovery in 1976 [1]. Compared to all previous outbreaks 
combined, the recent EVD epidemic was by far, the longest and largest [2]. From December 2013 when the first case was identified in the Gueckedou District of Guinea up till December 2014, over 9,800 estimated deaths were reported in Guinea, Liberia and Sierra Leon [3]. Occurring in countries with fragile health structures, the epidemic epitomized a major catastrophe in the hardest-hit areas.

While earlier outbreaks of EVD in Central and Eastern parts of Africa had limited geographical extension and little media coverage, news media interest in the 2014 Ebola epidemic was remarkably high. The globalizing style of the virus, the extraordinary high cases and transmissions to cities with major international airports (i.e. Lagos, Freetown, Conakry and Monrovia) seemed plausible reasons. In Ghana, where the risk of imported infection was estimated to be among the highest [4], news coverage for the epidemic heightened. News media perform a critical role in public health emergencies, when demand for accurate and timely information increases. They are also among the first-line receivers of risk information, and therefore occupy an important place in the social amplifications of risk [5]. Even with the rise of social media, enabled by increased use of internet, computers and smart phones, the news media continue to be essential because many people have limited access to information from medical literature especially on diseases about which the public is unfamiliar [6].

When properly monitored and studied, statistics from news media can serve as feedback mechanism on emergency response intervention. Data from either news or social media can also provide us with quantitative indicators of negative emotions (e.g. fear, anger, and anxiety) and positive sentiments (e.g. happiness and calm), which in turn could be useful in community engagement strategies [7]. Equally, media misrepresentations of public health risk can lead to misinformation and public confusion. This, in relation to Ebola, is significant because misinformation about the disease and its containment protocols has in times of outbreak, led to mistrust, resistance and hostilities from local people [8].

The record size of the 2014 epidemic seems to have renewed varied research interest on Ebola virus. In a recent study, Lee-Kwan and colleagues [9] examined the cultural and community factors to safe burials of Ebola victims. Earlier in October, 2014, the international spreading risk of the outbreak to other parts of Africa and beyond was similarly investigated [4]. A few others [10,11], have also studied the use of digital and culturally-centered health communication efforts in the context of the outbreak. Despite these investigations, important gaps, nonetheless, exist in current knowledge. Studies of public sentiments on Ebola and perceptions of risk exposure expressed through the news media are lacking. The few attempts in this regard have focused largely on developed countries particularly, the US [12,13], whereas vast amount of data in West African countries remain understudied. This paper is the first to study the content of Ghanaian newspapers' coverage for the 2014 Ebola outbreak. The study aims to describe and analyze the central themes which characterized media representations of the risk of Ebola outbreak in Ghana.

\section{Method and Sample:}

A quantitative content analysis (CA) was employed to study news media reportage of the risk of Ebola outbreak in Ghana following the 2014 Ebola epidemic in parts of West Africa. Two daily newspapers, the Daily Graphic and Today were sampled for the study. The Daily Graphic newspaper is the oldest in Ghana and was purposively selected because it is widely read and has the highest daily circulation across the country. The selection of Today in contrast was done by means of simple random sampling. An online search was conducted in the months of May and June, 2017 using key words including 'Ebola virus in 2014, 'Ghana', 'Daily Graphic' 
and 'Today newspaper'. All hits with Ebola in the headline or in the main story were retrieved and screened to ensure that only articles from the selected newspapers were retained. The search in total retrieved 332 articles consisting of news, editorials, columns, and opinion articles. For inclusion, news articles needed to directly report on the threat of Ebola in Ghana; thus, news articles on different subjects about Ghana which contained passing references to Ebola were not included. The second criterion was that news articles needed to contain information about the risk of Ebola in Ghana which had been published after $31^{\text {st }}$ December, 2013 and before January $31^{\text {st }}$, 2015. By these criteria, 172 articles were eliminated, leaving a final sample of 156 news articles for the study. This is illustrated in figure 1.

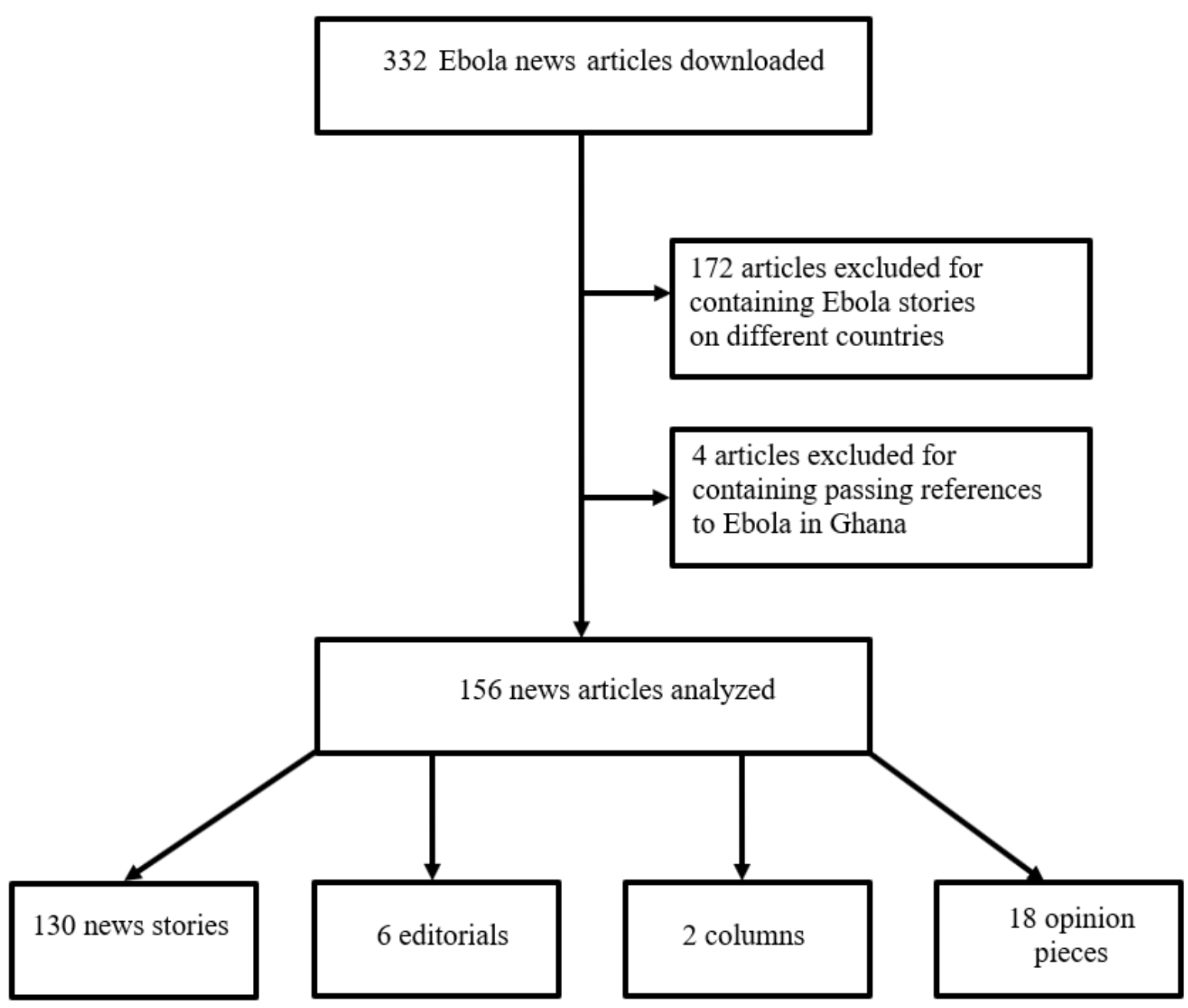

Figure 1: study flow chart

\section{Coding}

An initial review of 50 randomly selected news articles by the author informed a categorization of the data into 'general' and 'thematic' categories. A complete coding manual was then developed to guide the process. Coding for the general category included story type (news, editorial, column, and opinion), newspaper (Daily Graphic, Today), news source (Daily Graphic, Today, City FM, Joy news, other) story length, month (January - December 2014). Codes for the thematic category in contrast, comprised the following: Ebola education, suspected cases of Ebola in Ghana, misinformation about Ebola, concerns about Ghana's 
preparedness, support for Ebola prevention, critique of Ebola risk handling, effects of Ebola, assurances on Ebola preparation and other.

To guarantee inter-coder reliability, a detail story analysis form, which contained coders' initials, the general and thematic categories was used to guide coders. Three independent coders (the author and two graduates, who were given training prior to the exercise) carried out the coding, with codes by the author serving as control. Inter-coder reliability test was performed by randomly selecting and double-coding $20 \%$ of the sampled news articles. Cohen's Kappa for the thematic categories (article theme) was 0.71, while for the general categories, news source and news story type yielded inter-coder reliability scores of 0.91 and 0.85 respectively.

\section{Data analysis}

Data analysis was performed using SPSS version 20. Descriptive statistics involving frequencies and percentages were run to describe the sampled article characteristics, and to allow for meaningful understanding of the data.

\section{Results}

During the 2014 Ebola virus outbreak in parts of West Africa, the Daily Graphic and Today newspapers in Ghana published 332 stories about the epidemic. Of the 156 news articles which met the inclusion criteria and were thus analyzed, the Daily Graphic newspaper, accounted for $40 \%$ of both newspaper type and primary source of newspaper stories on EVD. Today newspaper in contrast, contributed $60 \%$ of newspaper type, and $22 \%$ of primary source of newspaper story. The analysis in table 1 shows that Today newspaper, compared to the Daily Graphic newspaper, published more secondary news on the epidemic. Joy News (25\%) and City FM (8\%) were the common sources of Ebola news for Today newspaper besides itself (22\%).

The majority (83\%) of Ebola information in the news media was presented as news stories. A modest number of opinion articles (11.5\%) also constituted a common source of Ebola information while editorial and column news articles were the least forms of news media information on the epidemic. Put together, media coverage for the threat of Ebola virus outbreak in Ghana reflected nine salient themes, defined in table 2.

The analysis also found that, four of the nine identified themes accounted for over half (58\%) of media reporting on Ebola risk in Ghana. These included concerns about the country's preparedness (17\%), support for Ghana's preparation for the outbreak (16\%), public education on the virus (14\%) and assurances on Ghana's readiness (11\%). Less dominant themes such as suspected cases of Ebola in Ghana and effects of the threat of Ebola also had a regular reportage of $9.5 \%$ and $9 \%$ respectively. The results further showed that two themes: misinformation about Ebola and critique of Ebola risk handling had the smallest percentage coverage of 3.5\% and $5.5 \%$ respectively. 
Table 1 News article Characteristics
$\mathrm{N}(156)$
$\%$

Newspaper type

Daily Graphic

62

39.7

Today

94

60.3

News story type

News

130

Editorial

6

Column

2

Opinion articles

18

News original source

Daily Graphic

62

Today

34

Joy news

39

25

City FM

13

8.3

Other

8

5.1

Table 2 Definition of Ebola news themes based on coverage

Theme

1. Concerns about Ghana's preparedness

2. Support for Ebola preparation in Ghana

3. Ebola education

\section{Assurances on Ebola preparation}

5. Suspected cases of Ebola in Ghana

\section{Definition}

Messages in this theme included fears expressed by healthcare workers about their readiness to handle Ebola patients; complaints about porous border control systems including but not restricted to lack of screening at entry points; worries about inadequate isolation and treatment centers; and reservations about some hospitals' capacity to conduct Ebola test

This comprised news stories on trainings for frontline health workers, material and logistical contributions to enhancing Ghana's preparation for the outbreak by the government, the corporate world, diplomatic community and development partners

This included news articles on sensitizations and public education on the Ebola virus disease - mode of spread, signs, symptoms, risk factors, prevention techniques, where and when to report for medical care

These were messages from political leaders and leadership of Ghana's health sector guaranteeing readiness for any eventuality

This included news stories on suspected Ebola infections in the country and laboratory test on alleged cases 
6. Effects of Ebola

7. Critique of Ebola risk handling

8. Misinformation about Ebola

9. Other
Comprised news messages about the impact of the threat of Ebola particularly on education, social life, entertainment, and business activities

News articles that criticize or commend the efficacy of response mechanisms vis-à-vis the threat of Ebola

News stories about Ebola virus diseases that contain medically incorrect statements about the disease, including traditional and religious claims on Ebola treatment and prevention

Messages in this category included miscellaneous news stories about the virus including but not limited to conspiracy theories about Ebola, travel warnings, calls for specific interventions etc.

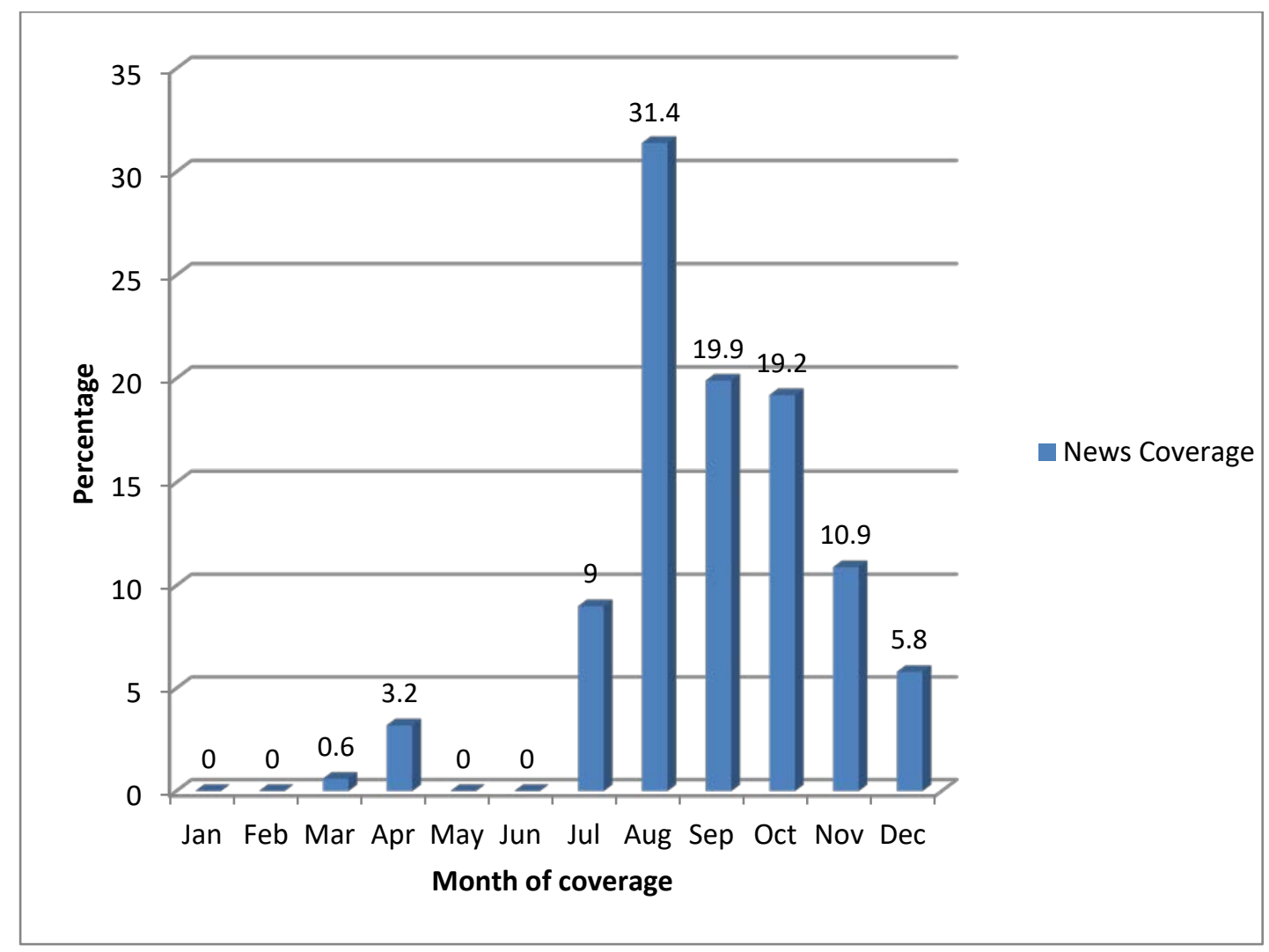

Figure 2: Monthly coverage of Ebola of news, January - December 2014

The regularity of the nine identified themes is illustrated in both figure 2 and table 3 . The analysis showed that, by March, 2014, only 1 (0.6\%) news story had been reported on support for Ebola prevention in Ghana. This coverage unsurprisingly, followed the formal recognition of the then evolving infection in parts of Guinea as Ebola virus. The month of April saw an increase in news coverage for the epidemic from just 1 in March to 10 (3.2\%).

While news coverage for the risk of the epidemic in Ghana partly reflected crucial happenings in the worst affected countries, it is interesting to observe that the months of May and June had no coverage on any of the identified themes even though both cases and fatalities continued, particularly in June. From July, however, Ghanaian media coverage for the epidemic witnessed marked increase to about 9\%, peaked in August with 31.4\% and declined significantly in September to about $19.9 \%$. The decreasing coverage continued in October to about $19.2 \%$ 
through November (10.9\%) to December (5.8\%). Compared to other months, August and September had news coverage on all the 9 themes while October and November had coverage on 8 themes each. Coverage for concerns about Ghana's preparedness increased in July (4), peaked in September (12) and decreased considerably in October (3) and December (1). This perhaps explains a similar trend on coverage in respect of support for Ebola readiness in Ghana, which started in July (1) and increased consistently up to November (7) before diminishing to 3 in December. The results equally showed that news coverage for suspected imported cases of Ebola virus into Ghana was highest in July (7) and August (6), and almost disappeared in November (1) and December (1). This high reportage on suspected Ebola cases in July and August, might have contributed to a corresponding surge in coverage for education on the contagion in the months of July (6) and August (6). Other themes such as effects of the outbreak (9) and critique of Ebola risk handling in Ghana (5) were reported prominently in August, followed by significant declines in subsequent months.

\section{Discussion}

This study is the first to analyze Ghanaian news media's coverage for the 2014 Ebola epidemic in West Africa. From obscurity in the first half of 2014, media coverage for the risk of Ebola outbreak in Ghana proliferated in July, and peaked in August. This watershed seems to have been heavily shaped by four external factors - the swift increases in July/August caseload, the declaration of Ebola as public health emergency of international concern, the exportation of Ebola to Nigeria on July $20^{\text {th }}$ and the infection of two American workers in Liberia, Kent Brantly and Nancy Writebol on July $27^{\text {th }}$. The results showed that, as media reporting of Ebola risk in the country increased, nine major themes became salient and characteristic of the coverage. These included concerns about the Ghana's preparedness, support for Ebola preparation, education on Ebola, assurances on Ghana's readiness, suspected cases of Ebola, effects of Ebola threat, critique of Ebola risk handling, misinformation about Ebola and other. Away from the usual research focus on Ebola treatment and vaccine trials, the findings of this study contribute to an understanding of the broad impact of the recent Ebola outbreak on various sectors of the population. While each of the identified themes may offer useful lessons for future occurrences, a few perhaps deserve further discussion.

The finding that concerns on Ghana's preparation for the Ebola virus was the leading theme in media coverage, requires policy attention. Widespread concerns in an emergency situation can undermine public health surveillance. Infected persons can abscond from isolation centers out of fear, and others may become hostile to emergency workers. A closer examination of this theme showed high prevalence of fear among the public and healthcare workers. In some instances, medical staff actually panicked in handling suspected Ebola patients (Today, 19/11), while in others, suspicious patients in dire need of medical attention were simply abandoned (Today, 19/11). This result is similar to earlier findings in Ethiopia, where Abebe and colleagues [14] found Ebola caused fears among more than 58\% of healthcare professionals. It also concurs with previously reported episodes of fear, avoidance and flight from hospitals by medical staff in earlier outbreaks of Ebola [8]. Key among the drivers of Ebola triggered concerns was general perception of weak epidemic preparedness in Ghana. Limited availability of personal protective equipment, porous borders and Ghana's struggle to contain an outbreak of cholera at the time [15], lent credence to the perceptions of weak preparedness. In one article for instance, the writer was alarmed that: "In 2014, cholera still remains an epidemic Ghana has been unable to effectively combat and now, we have to deal with almighty Ebola disease which we are told is the deadliest virus the world has ever seen'(Today, 08/12). Similar coverage by the Daily Graphic observed that 'both the frontiers at Aflao and northern Ghana 
are leaking badly so far as illegal entries are concerned. Besides, those who enter are not screened before mingling with our indigenes; this is ... happening at a time the Ebola scare is being magnified' (Daily Graphic, 06/09).

Another interesting finding which perhaps involves positive lessons for Ghana's health system is the result that, news coverage of Ebola threat in Ghana had fewer instances of misinformation. The few misrepresentations about the epidemic were commonly centered on traditional and religious claims on the causes of Ebola and treatment opportunities. While this tendency was helpful, it may have also been the result of a relatively high public education on the virus which started as early as April (5), stopped in May/June, and continued in July (6) up to December (3). Since this analysis was limited to print media sources, it is also likely that public education on the virus was much higher than the present estimates. This finding on instances of misinformation on Ebola, however, differs from analysis of Ebola related misinformation on social media in Guinea, Liberia and Nigeria in the first week of September 2014, which found that the majority of tweets (55.5\%) and retweets (58.9\%) on Ebola contained medical misinformation [16]. This variation understandably, could be due to the gate keeping structures in mainstream media, which inter alia, can verify information prior to publication.

While it is difficult to ascertain the true impact of the 2014 Ebola crisis in non-infected countries such as Ghana, media coverage on the effect of the Ebola threat points to a wider impact on different sectors of the Ghanaian society. The analysis showed that, the effect was positive for some sectors and negative for others. In the health sector for instance, the threat stimulated both short and long term investments in epidemic preparedness. These included but were not limited to emergency constructions of three new isolation centers and procurement of new medical equipment. Other sectors such as education, was negatively impacted in respect of rescheduling of school periods, learning time lost to screening for Ebola etc. The threat also lowered commodity prices for some goods e.g. game meat, and thus adversely affected the livelihoods of many Ghanaians (Daily Graphic, 05/08; Today, 15/08). Game meat, known popularly as 'bush meat' is a delicacy in Ghana, providing employment to many in the value chain (e.g. hunters, wholesalers, retailers, game meat kebab sellers and bar operators). Although the game meat etiology of the recent outbreak has been contested [17], this effect seems logical given the risk of animal to human transmission of the deadly contagion. 
Table 3 Frequency and Percent of Ebola news theme by month, January - December, 2014

\begin{tabular}{|c|c|c|c|c|c|c|c|c|c|c|c|c|c|c|c|}
\hline \multirow[t]{2}{*}{ Recurring theme } & \multicolumn{12}{|c|}{ Month of publication } & \multirow{2}{*}{$\begin{array}{c}\text { Theme } \\
\text { total }\end{array}$} & \multirow[t]{2}{*}{ Percent } & \multirow{2}{*}{$\begin{array}{l}\text { Percent } \\
\text { of cases }\end{array}$} \\
\hline & Jan & Feb & Mar & Apr & May & Jun & Jul & Aug & Sep & Oct & Nov & Dec & & & \\
\hline $\begin{array}{l}\text { Concerns about } \\
\text { preparedness }\end{array}$ & & & & 2 & & & 4 & 9 & 12 & 3 & 3 & 1 & 34 & $17 \%$ & $21.8 \%$ \\
\hline $\begin{array}{l}\text { Support for Ebola } \\
\text { preparation }\end{array}$ & & & 1 & & & & 0 & 7 & 6 & 8 & 7 & 3 & 32 & $16 \%$ & $20.5 \%$ \\
\hline $\begin{array}{l}\text { Assurances on } \\
\text { preparation }\end{array}$ & & & & 1 & & & 2 & 6 & 4 & 7 & 1 & 1 & 22 & $11 \%$ & $14.1 \%$ \\
\hline $\begin{array}{l}\text { Suspected case of } \\
\text { Ebola in Ghana }\end{array}$ & & & & 1 & & & 7 & 6 & 3 & & 1 & 1 & 19 & $9.5 \%$ & $12.2 \%$ \\
\hline $\begin{array}{l}\text { Critique of Ebola } \\
\text { risk handling }\end{array}$ & & & & 1 & & & & 5 & 2 & 1 & 2 & & 11 & $5.5 \%$ & $7.1 \%$ \\
\hline $\begin{array}{l}\text { Misinformation } \\
\text { about Ebola }\end{array}$ & & & & & & & 1 & 1 & 1 & 3 & & 1 & 7 & $3.5 \%$ & $4.5 \%$ \\
\hline Other & & & & & & & & 11 & 8 & 7 & 3 & & 29 & $14.5 \%$ & $18.6 \%$ \\
\hline $\begin{array}{l}\text { Monthly total } \\
\text { (\%) }\end{array}$ & - & - & $0.6 \%$ & $3.2 \%$ & - & - & $9 \%$ & $31.4 \%$ & $19.9 \%$ & $19.2 \%$ & $10.9 \%$ & $5.8 \%$ & - & - & - \\
\hline
\end{tabular}




\section{Limitations}

This study notwithstanding its significance has several limitations. The study used data from only two print media outlets in Ghana. This implies that Ebola related discussions and perspectives shared through radio and television stations in Ghana were not included. Another important shortcoming of the study is the likelihood that the sampled news stories might not be representative due to the relatively high illiteracy rate in Ghana; it is conceivable that the data for this study may reflect the sentiments of the well-educated, who unlike their illiterate counterparts, can express and share their experiences through the print media. Finally, mainstream media publications compared with social media, have several gatekeeping structures which might modify or exaggerate individuals' experiences and sensitivities to public health epidemics.

\section{Conclusion}

Media coverage for the risk of an Ebola outbreak in Ghana during the 2014 Ebola epidemic was studied using quantitative content analysis. The study identified nine important themes which characterized media reporting of the epidemic: concerns about the Ghana's preparedness, support for Ebola preparation, education on Ebola, assurances on Ghana's readiness, suspected cases of Ebola, effects of Ebola threat, critique of Ebola risk handling, misinformation about Ebola and other. These themes provided valuable understanding on public responses to the threat and its widespread impact on the Ghanaian society.

It is significant to recognize that while vaccinations and medical treatments are helpful ways of controlling infectious disease outbreaks, they probably would not be the most effective way to approach unfamiliar infections. The biggest resources for containment of deadly epidemics of Ebola's kind are robust surveillance and containment capacity, including well-equipped medical staff, with reasonable protection against the perils of working with diseases of highcase fatality. The extensive impact of ICT in this day and age will be helpful in building robust response mechanisms in Ghana. These could be ehealth tools designed to facilitate community mobilization, logistics management, contact tracing and timely data collection. With a high smartphone penetration rate in Ghana, the use of ehealth tools will effectively situate the country to move beyond facility-based disease surveillance, to digitally driven participatory engagement of populations at risk. Further research on how ICT - based surveillance strategies involving media and mobile data platforms can strengthen Ghana's surveillance capacity will be useful.

\section{Conflict of interest}

I declare that there is no conflict of interest.

\section{References}

1. 2014. The Lancet Infectious Diseases. Ebola in West Africa [Editorial]. Lancet. (Sep), 14.

2. Briand S, Bertherat E, Cox P, et al. 2014. The International Ebola Emergency. $N$ Engl J Med. 371, 13. PubMed https://doi.org/10.1056/NEJMp1409858

3. WHO.2015. Ebola Situation Report. WHO $4^{\text {th }}$ March, 2015 
4. Gomes MFC, Piontti AP, Rossi L, et al. 2014. Assessing the International Spreading Risk Associated with the 2014 West African Ebola Outbreak. PLOS Currents Outbreaks. 1. doi:10.1371/currents.outbreaks.cd818f63d40e24aef769dda7df9e0da5. PubMed

5. Kasperson RE, Renn O, Slovic P, et al. 1988. The Social Amplification of Risk: A Conceptual Framework. Risk Anal. 8, 2. https://doi.org/10.1111/j.1539-6924.1988.tb01168.X

6. Chapman S, Lupton D. Fight for public health: principles and practice of media advocacy. London: British Medical Journal Publishing, 1994

7. Chun-Hai Fung I, Hos Tse ZT, Cheung C, Miu AS, Fu K. 2014. Ebola and the social media. Lancet. $\cdots$, , 384. PubMed

8. Sokol DK. From anonymity to notoriety. Historical problems associated with outbreaks of emerging infectious diseases; a case study: Ebola hemorrhagic fever. Master Degree Thesis in Social and Economic History. University of Oxford, 2002

9. Lee-Kwan HS, DeLuca L, Bunnell R, et al. Facilitators and Barriers to Community Acceptance of Safe, Dignified Medical Burials in the Context of an Ebola Epidemic, Sierra Leone, 2014, J Health Commun 2017; 22: sup1, 24-30. DOI: 10.1080/10810730.2016.1209601

10. Sastry S and Dutta JM. Health Communication in the Time of Ebola: A Culture-Centered Interrogation. $J$ Health Commun 2017; 22:sup1, 10-14. DOI: 10.1080/10810730.2016.1216205

11. Roberts H, Seymour B, Fish II AS, Robinson E and Zuckerman E. Digital Health Communication and Global Public Influence: A Study of the Ebola Epidemic. J Health Commun 2017; 22:sup1, 51-58. DOI: 10.1080/10810730.2016.1209598

12. Towers S, Afzal S, Bernal G, et al. 2015. Mass Media and the Contagion of Fear: The Case of Ebola in America. PLoS One. 10(6), e0129179. doi:https://doi.org/10.1371/journal.pone.0129179. PubMed

13. Basch CH, Basch CE, Redlener I. 2014. Coverage of the Ebola Virus Disease Epidemic in Three Widely Circulated United States Newspapers: Implications for Preparedness and Prevention. Health Promot Perspect. 4(2), 247-51. doi:10.5681/hpp.2014.032. PubMed

14. Abebe BT, Bhagavathula AS, Tefera YG, et al. 2016. healthcare professionals' awareness, knowledge, attitude, perceptions and beliefs about Ebola at Gonder University Hospital, Northwest Ethiopia: a cross-sectional study. J Public Health Africa. 7, 570. PubMed https://doi.org/10.4081/jphia.2016.570

15. WHO. 2014. Situation report on cholera outbreak in Ghana. WHO, 2 November, 2014

16. Oyeyemi OS, Gabarron E, Wynn R. 2014. Ebola, Twitter, and misinformation: a dangerous combination? BMJ. 349, g6178. doi:https://doi.org/10.1136/bmj.g6178. $\underline{\text { PubMed }}$

17. Gire SK, Goba A, Andersen KG, et al. 2014. Genomic surveillance elucidates Ebola virus origin and transmission during the 2014 outbreak. Science. 345, 1369-72. doi:https://doi.org/10.1126/science.1259657. PubMed 